\title{
Mathematical Model Applied to Green Building Concept for Sustainable Cities Under Climate Change
}

\author{
${ }^{1}$ Professor Dr. Md. Haider Ali Biswas (D) P , 2* M.Sc. Pinky Rani Dey \\ ${ }^{3}$ Asst. Prof. Md. Sirajul Islam (iD P, , M.Sc. Sajib Mandal
}

1 Mathematics Discipline, Science Engineering and Technology School, Khulna University, Khulna-9208, Bangladesh 2, 3 \& 4 Department of Mathematics, Bangabandhu Sheikh Mujibur Rahman Science and Technology University, Gopalganj8100, Bangladesh

E-mail 1: mhabiswas@gmail.com ,E-mail 2: pinkydey.math@gmail.com

E-mail 3: sirajulku@gmail.com, E-mail 4: sajibmandal1997@gmail.com

\section{ARTICLE INFO:}

\section{Article History:}

Received: 20 May 2021

Revised: 25 July 2021

Accepted: 11 August 2021

Available online 16 August 2021

\section{Keywords:}

Green Building;

Sustainable Cities;

Climate Change;

Mathematical Model;

Numerical Simulations.

\section{ABSTRACT}

Recently the effect of greenhouse gases (GHGs) is worldwide terrified anxiety to the public and scholars. Even this global problem is one of the great issues that continuously makes worrying the governments and environmentalists, but its solution findings are not out of the image at all. In this study, we have proposed and analysed a mathematical model for the solvable management of GHGs by sowing the seeds of green building dynamic systems. Moreover, in the model, the human community is used to enhance the production power of individuals of green buildings by absorbing the GHGs. The model is analysed by stability analysis at the equilibrium points: trivial and global equilibrium, and also by convincing the stability and instability of the system of equations. The behaviour of the propound model has been developed by numerical simulations which shows the rate of the fruitfulness of $G H G$ components.

JOURNAL OF CONTEMPORARY URBAN AFFAIRS (2022), 6(1), 36-50. https://doi.org/10.25034/ijcua.2022.v6n1-4

WwW.ijcua.com

Copyright @ 2021 by Professor Dr. Md. Haider Ali Biswas, M.Sc. Pinky Rani Dey, Asst. Prof. Md. Sirajul Islam \& M.Sc. Sajib Mandal

\section{Introduction}

In recent years, green building has become a powerful tool to fight against global warming. Generally, green building is not only a specific construction method but also a gathering of techniques, technologies and equipment which are applied into construction to make it

\section{*Corresponding Author:}

Mathematics Discipline, Science Engineering and

Technology School, Khulna University, Khulna-9208,

Bangladesh

Email address: mhabiswas@gmail.com 
environment friendly. All about green building targets to make a healthy construction by reducing its impact on the environment. A green building has a strong way of recycling, reducing, reusing and renewable resourcing of materials. A green building can reduce water and energy consumption, use eco-friendly building tools, minimize GHG emissions, inspire renewable abstraction, develop the environment with trees and roof gardens, etc. Green buildings help to fight climate change in two ways. Firstly, by performing energy efficiency and secondly, by promoting green communities. If green buildings are established inside any community, it can maximize their impact on a healthy environment undoubtedly.

Buildings, transportation, and industries are three well-recognised energy consumption sectors in worldwide (Mardiana \& Riffat, 2013). Both trade and residential buildings are responsible for consuming one-third energy of total energy than transport and industries (Gul \& Patidar, 2015; Yau \& Hasbi, 2013). In developed countries, only buildings are liable to consume $35 \%$ - $40 \%$ energy of total energy (Gong \& Song, 2015). According to the 4th assessment report of the Intergovernmental Panel on Climate Change (IPCC), the emission of $\mathrm{CO}_{2}$ by building sectors was 8.6 billion metric tons in 2004 and it was predicted to arise about 15.6 billion metric tons by 2030 (Metz et al., 2007). After reaching in 2010, the level of $\mathrm{CO}_{2}$ emission was almost grown up to 8.8 billion metric tons for building sectors (Edenhofer et al., 2014). According to the Climate Action Tracker (CAT), globally $27 \%$ of energy-related $\mathrm{CO}_{2}$ are emitted and $30 \%$ of energy are used for building operation both in manufacturing and constructing (Lebling et al., 2020). Also, the Sustainable Buildings and Climate Initiative (SBCl) predicts that about $33 \%$ of $\mathrm{GHG}$ emissions and $40 \%$ of energy consumption are done by the worldwide building sectors (Gong \& Song, 2015). After examining additionally 650 life cycle evaluations of GHGs it is found that as long as a building lasts it emits a maximum rate of GHGs which are mostly responsible for climate change (Röck et al., 2020). The result of the increasing GHGs record an alarming rate of global warming in the last decades. The temperature of the earth becomes warmer day by day. The average rising in global temperature was only $0.290 \mathrm{C}$ in $1981-1990$ but it reached $0.82^{\circ} \mathrm{C}$ in $2011-2020$ (Roston, 2021). It is predicted that global warming can reach an alarming rate by 2050 (Lebling et al., 2020). Due to global warming, the environmental ecosystem is getting very damaged in recent years (Biswas et al., 2016). There are some adverse effects of global warming in the environment such as it rapidly declines the groundwater level (Islam \& Biswas, 2020), it decreases the plankton density in marine ecosystems as well as oxygen-producing rate by warming seawater (Mandal et al., 2020), it also becomes a threat for the living beings near coastal areas introducing natural destructive phenomena (Mandal et al., 2021). Furthermore, cities can become $4^{\circ} \mathrm{C}$ hotter by 2100 than rural areas (Zhao et al., 2021). Day to day the temperature of cities becomes high not only for industrialization and population density but also for unplanned construction. So, it is necessary to take a look at building construction technologies not only to cut GHGs but also to save cities. There exists a lot of techniques to reduce GHG emissions from buildings (Pacala \& Socolow, 2004). To minimize the level of GHG emissions, carbonreducing techniques and renewable energy segments need to develop (Pal, 2017). The expansions of renewable energy strategies like bioenergy potential (Smeets et al., 2007), geothermal energies (Pollack et al., 1993), solar, hydro, ocean, wind hybrid sectors (Rezaie et al., 2011) can boost the energysaving techniques of building. Generally, the application of renewable energies without using fossil fuels is called zero carbon emission building (Kaygusuz, 2007). Moreover, to lessen the energy consumption the residential apartments can be decorated in a north-south oriented configuration, but if it is not possible then the solar chimney will be a good alternative (Rahbarianyazd \& Raswol, 2018). It also needs to keep in mind that, buildings need to be environmentally friendly, technically attractive and possibly cost effective (Rezaie et al., 2011). Adopting the "Smart Cities Plan" with green infrastructure will be a standard solution (Zhao et al., 2021). It is also remarked that cities are mostly influenced by the impact of globalization since cities are the main ruler of any country (Kara, 2019). But sustainable smart city planning is a pleasant and environmentsaving policy with high-quality life and economy (Sasanpour, 2017). The green infrastructure can become an effective tool for industrialization without harming the natural elements (Reza et al., 2017). An experimental comparison of sustainable green infrastructure is demonstrated for different environmental products of building regions (Nyári, 2011). 
Generally, green infrastructure indicates green buildings, which is a good initiative to make sustainable construction for smart cities (Shawkat et al., 2018). Green building is an ecological indicator against all kinds of toxic emissions (Liu \& Lin, 2016). Each part of a green building is made to fight against all kinds of ecological obesity. Green building is quite helpful to reduce $20 \%$ of building-related GHGs emissions (Nyári, 2011). Green buildings can reduce about $30 \%-40 \%$ of energy consumption, lessen about $33 \%$ of global GHG emissions, reduce $30 \%$ of water consumption, reduce $50 \%$ of solid waste, provide better indoor air quality, etc (Reddy, 2016). In green buildings, the indoor temperature quality can be improved by the buildings green roof impact (Jaffal et al., 2012). The United States Green Building Council (USGBC) works for all possible countries to make people concern about the sustainability of the earth for fighting against GHG emissions, for example, the logical role of green buildings had statistically analysed almost all over India on behalf of GRIHA (Tathagat \& Dod, 2015), China recently adopts green building technologies to reduce carbon emission (Wu et al., 2017), etc. Furthermore, many European and South Indian countries like Manila, India, New York, Mexico, Tokyo, Singapore, Jakarta, Beijing, etc. are adopted carbon footprint technologies for developing urban areas (Sovacool \& Brown, 2010). Mathematical modelling is widely used to demonstrate various types of real-life problems to create a good prognosis, determination, arrangements and respiration mechanisms (Mondal et al., 2017). Any kind of interaction or affirmation relationships of species is perfected to explain by mathematical modelling. In mathematical modelling, we use the changing rate of any subject according to time, which is expressed in terms of differential equations. The differential equation shows the natural behaviour of the species to cope up with the environment ecosystem. There are a lot of dynamics of mathematical modelling, for example, the SIS epidemic model, the Logistic model, the Lotka-Volterra predator-prey model, the SEIR disease model, the SIR epidemic model, the optimal control strategic model, etc. Each of the models is used for describing the different-different state of environmental ecology. For example, the SIS model is used to describe the rate of natural births-deaths and disease-related deaths with time (Hethcote \& van den Driessche, 1995), the
SIR model is used to discuss the spread of epidemiology (Parvin et al., 2020), the LotkaVolterra model describes the ecological dynamics of the interaction of the species where one is prey and the other one is a predator (Zhu \& Yin, 2009), the optimal control strategic model generally discusses the control dynamics of any kinds of an outbreak (Shanta \& Biswas, 2020), the Logistic-Model is used to describe the carrying capacity of any species in the environment (Marchetti et al., 1996), etc. The study deals with green building technologies and the emission of GHGs by human communities and their correlations. The study is aimed to discuss the impact of green building by absorbing GHG for human communities. We have proposed a mathematical model which contains a set of non-linear ordinary differential equations to make the GHG components beneficial by integrating them into green building technologies. The model is analytically analysed first and then numerical simulations are performed. At each equilibrium point, the stability analysis has been observed with the state variables positivity test. The analytical result is examined with the help of numerical discussion to approve the model.

\section{Material and Methods}

We are living in such a present world that is fully organized with developed artistic creation, where civilization means highly performed techniques and technologies in every part of daily necessities. To cope up with this modern era we have forgotten about the limitation of natural eco-balance unfortunately. This results in a curse that, 2020 is addressed as the warmest year on record (Hausfather, 2020). It is a very expected result that the Arctic sea ice line is noticed at a record level low than before (Hausfather, 2020). Can we think for a while about our future era? If the global warming issues can't be kept in control the earth will not remain worth for sustain. It is seriously high time to cut GHGs to save our future world. It is a great remark that the developed countries use their land not as much for forestation but much more for industrialization (Hanley, 2015). The World Resources Institute CAIT Climate Data Explorer has made a statistical overview on global GHG emissions shown in Figure 1. The United States and China are the top GHG emission countries. Figure 1 displays the total amount of GHG emissions for top GHG emitted countries in 1990-2012 (Hanley, 2015). 


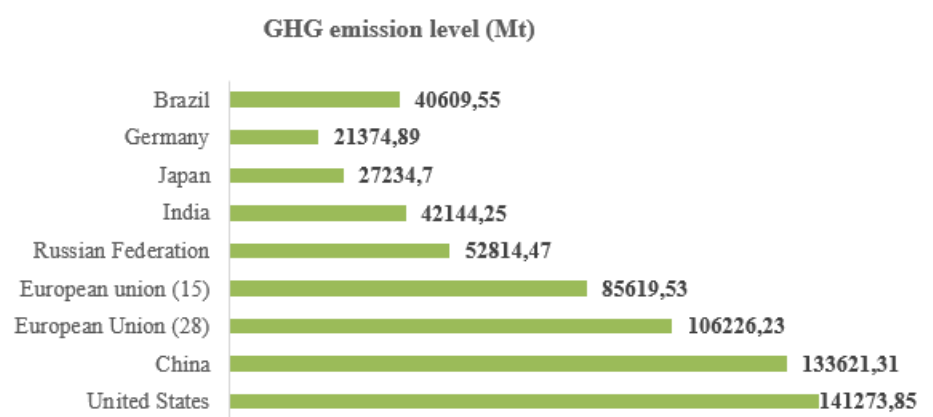

Figure 1. Emissions of GHG by the most GHG emitting countries in 1990-2012.

The last official commencement on climate affairs was carried out by the United Nations (UN) in December 2015 to discuss the global toxic emission which is known as Paris Agreement (Yilmaz, 2021). According to Paris Agreement, all the countries signed to limit global warming "well below" to $2^{\circ} \mathrm{C}$ and if possible to $1.5^{\circ} \mathrm{C}$ (Lebling et al., 2020). To fulfil the target each country needs to reduce at least half of presents emission that is addressed in the Paris Agreement (Broom \& Gray, 2020). It is quite hard but it is hardly necessary to save our world literally. But it is a matter of sorrow that, China emitted 14,093 MMt GHGs in 2019 which was $27 \%$ of the total GHG emissions and the second-highest GHG emitter was the US which emitted about $11 \%$ of the total GHGs (Larsen et al., 2021). The matter of frustration is, in 2020 again the top highest GHG emitter was China. In 2020 China again emitted 14,400 MMt GHGs, which was $1.7 \%$ more than the prior year (Grant et al., 2021). Due to excess GHGs emissions, global warming has tied the year 2020 with 2016 around $1.2^{\circ} \mathrm{C}$ hotter than before (Roper, 2021). For the extreme increase in GHGs the temperature is continuously rising day by day (Roston, 2021). Figure 2 represents the change of decades average temperature from 1951 to 2010 (Roston, 2021).

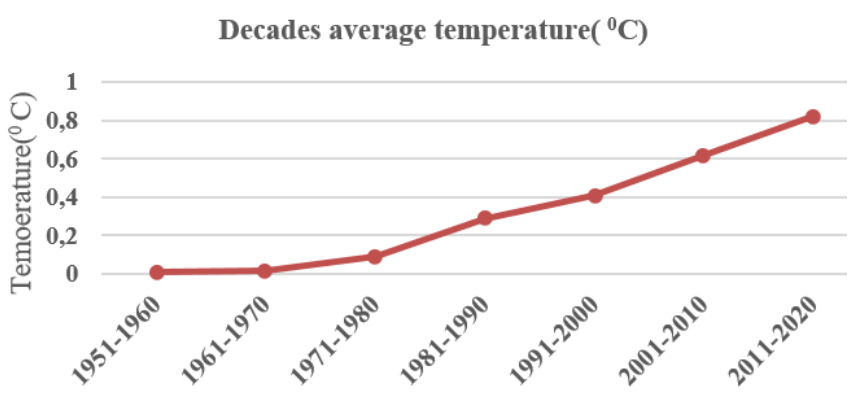

Figure 2. The rising rate of temperature from 1951 to 2020.

A common question is picked up in all the minds of environmentalists about the sustainability of the earth in the future. How GHGs are produced and what are the main reasons? In one word we can say, the human community is the main victim. A huge number of people on many sides are responsible for maximum $\mathrm{CO}_{2}$ emissions. This large amount of $\mathrm{CO}_{2}$ contains other heat-trapping gas into the atmosphere and produce GHG components such as $\mathrm{CH}_{4}, \mathrm{~N}_{2} \mathrm{O}$, HFCs, PFCs, and $\mathrm{SF}_{6}$ which causes the increase of atmospheric temperature day by day. We are dreamt to make a bio-technical green building system where all of the GHG components are used to make them fertile. The green building can be any of a residential building, an industry, a factory, a commercial building, an educational institute, a hospital, etc. Suppose any industrial building is designed on the basis of green building technologies. The industrial building stands for refrigerating, airconditioning, foams, aerosol cans etcetera's production case whose main raw materials are fluorinated gases (HFCs, PFCs, and SF6). Since the green building holds a lot of plants that help to absorb $\mathrm{CO}_{2}$ by photosynthesis. Photosynthesis helps to keep the atmospheric temperature in control and also it is a source of food production. On the other hand, methane $\left(\mathrm{CH}_{4}\right)$ and nitrous oxide $\left(\mathrm{N}_{2} \mathrm{O}\right)$ have great use in biomass planting and fertilizer or manure application respectfully. The whole assumption is displayed in Figure 3. 


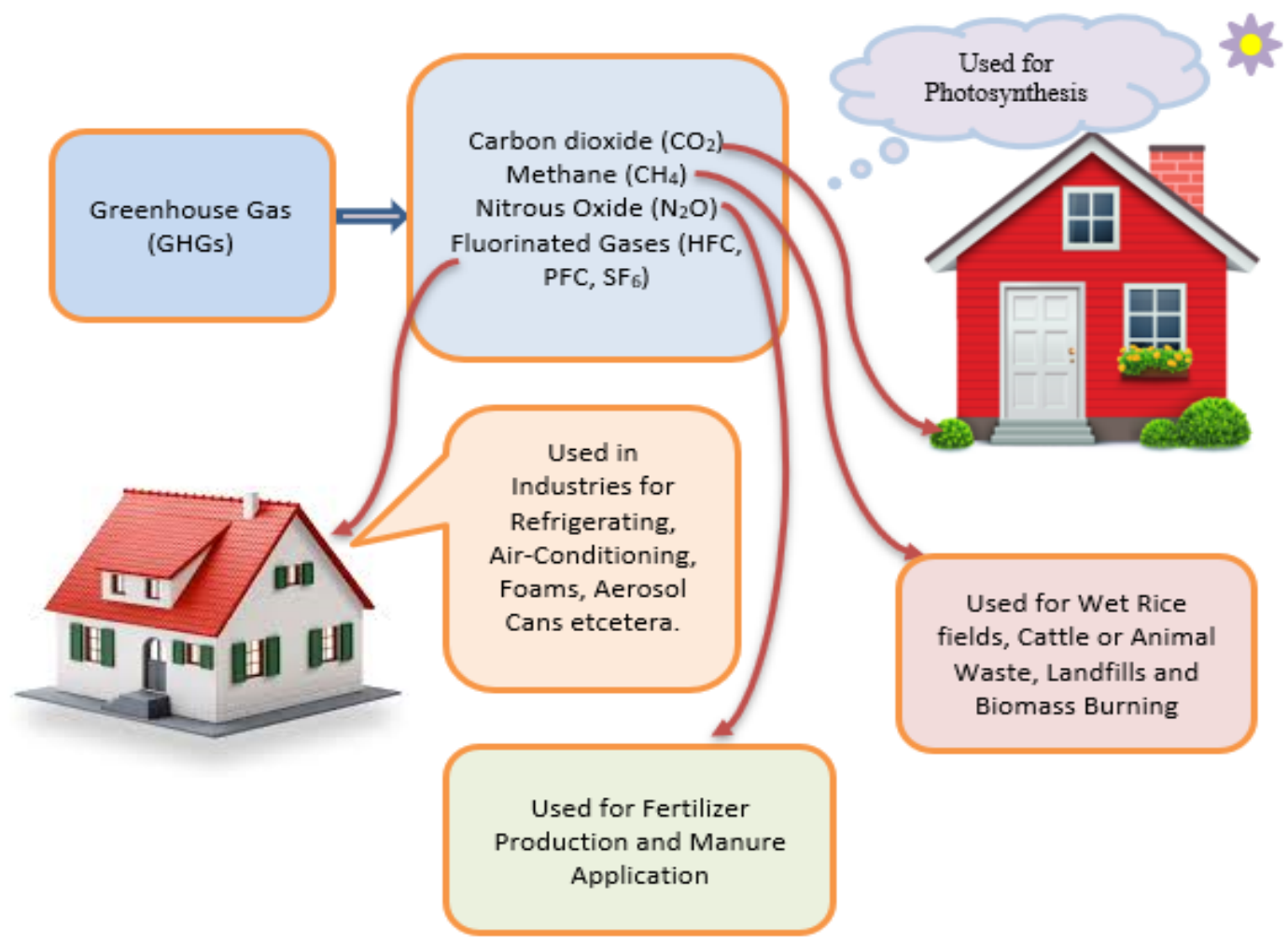

Figure 3. Implementation of GHG components to green building dynamic systems.

In our assumption, the GHG components have been planting into green building systems and made an artistic track like Figure 4 to establish a modelling procedure. We have made the methodological concept according to Figure 4. If there is a large amount of GHGs, green buildings absorb these GHGs and produce numerous numbers of energetic ingredients. The human community will become beneficial by consuming the energetic ingredients and again produce a large number of GHGs. Again, green buildings will absorb GHGs proportionally for reproducing ingredients.

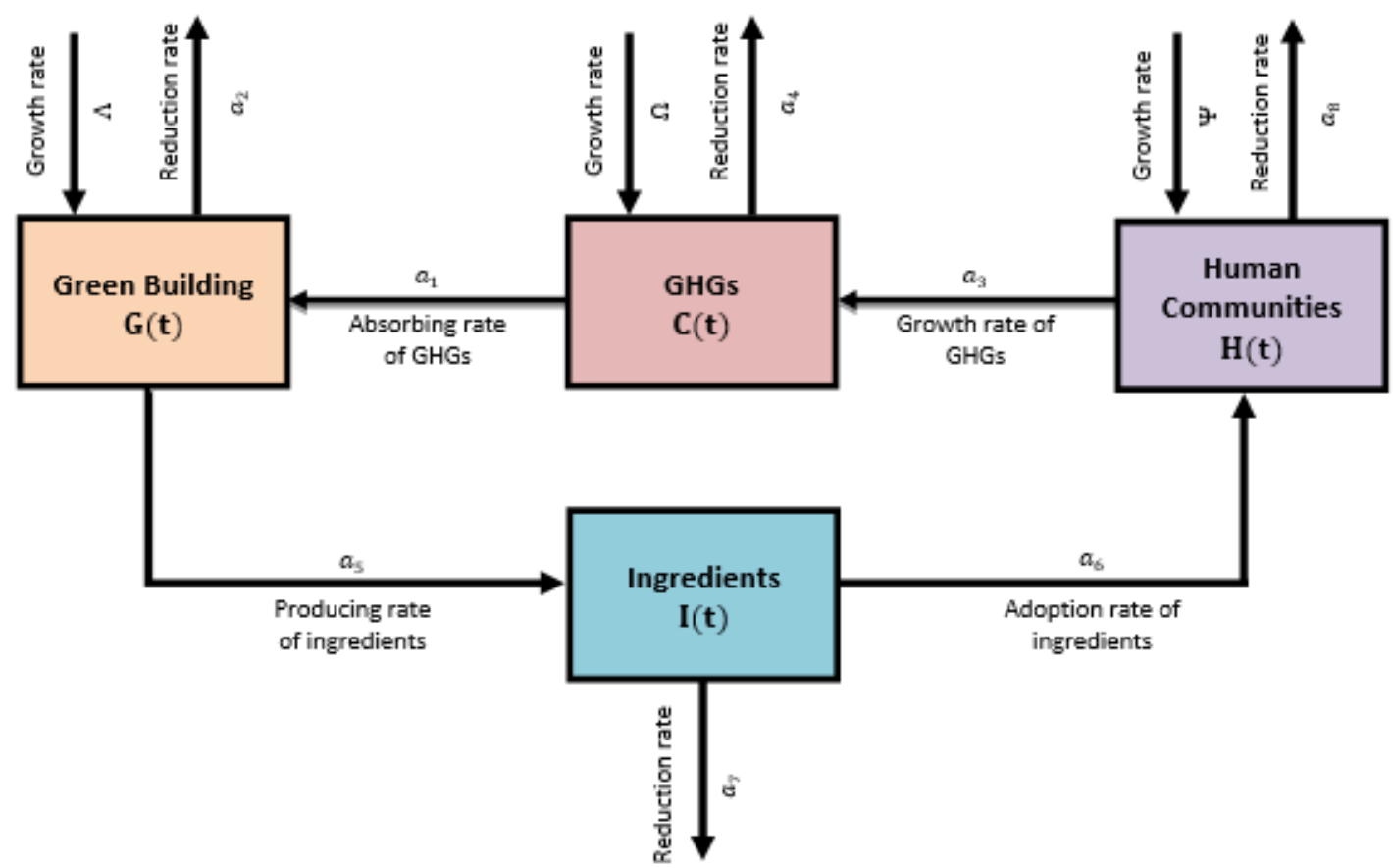

Figure 4. The schematic diagram describing the effect of green buildings on GHGs, ingredients, and human communities. 


\section{Model Formulation}

Mathematical modelling is one of the best weapons to illustrate the lifetime behaviour of any real-life problem. To analyse the impact of global warming because of extreme GHG emissions on sustainable cities, a mathematical model has been formulated by considering four state variables as the number of green buildings, the amount of GHGs, the energetic ingredients producing from green buildings and the human communities of a certain area. Here it is typically mentioned that ingredients are not any kinds of tools it means the environment-friendly effects that are made by green buildings like solar energies, water betterments, temperature assessments, renewable energies, economical managements, food technologies, etc. The proposed model aims to describe how GHG emissions can be controlled by implementing green buildings. Figure 4 describes the interrelation of state variables for the modelling procedure.

$$
\begin{aligned}
& \frac{d G}{d t}=\Lambda+a_{1} G C-a_{2} G \\
& \frac{d C}{d t}=\Omega-a_{1} G C+a_{3} H C-a_{4} C \\
& \frac{d I}{d t}=a_{5} G I-a_{6} H I-a_{7} I \\
& \frac{d H}{d t}=\Psi+a_{6} H I-a_{8} H
\end{aligned}
$$

To establish the green building model, let us consider the green building variable $G(t)$ where $\frac{d G}{d t}$ defines the rate of change of $G(t)$ at any time $t$. In the model, $\frac{d C}{d t}$ represent the rate of change of GHGs $C(t)$ at any time $t$. Also, the green building since produced a number of energetic ingredients $I(t)$ so at any certain time $t$ the rate of change of $I(t)$ is denoted by $\frac{d I}{d t}$. Again let $\frac{d H}{d t}$ identifies the rate of change of the human community $H(t)$ at any certain time $t$. Here $\Lambda, \Omega$ and $\Psi$ be the quantity of green building $G(t)$, GHGs $C(t)$ and human community $H(t)$ at any certain time $t$ respectively. A mathematical model with four state variables is formulated in the following form according to the schematic diagram described in Figure 4:

with the initial conditions, $G(0)=G_{0} \geq 0 ; C(0)=C_{0}>0 ; I(0)=I_{0} \geq 0 ; H(0)=H_{0} \geq 0$.

The parameters that are used in the proposed model with both their description are given in Table 1. If green buildings are interacting with GHGs, it reduces $20 \%$ of GHGs by consumption (Wang et al., 2014), so we use $a_{1}$ to define the absorption rate of GHGs by green buildings. In the model $a_{3}$ and $a_{6}$ defines the producing coefficient of GHGs and the absorption coefficient of ingredients by human communities respectively. Also, in the model $a_{5}$ is used to indicate the number of ingredients that the green building produces.

Table 1. Descriptions of the model parameters with their corresponding values.

\begin{tabular}{|c|l|}
\hline Parameters & \multicolumn{1}{|c|}{ Parametric statement } \\
\hline$\Lambda$ & Amount of green building. \\
\hline$a_{1}$ & Absorption rate GHGs by green buildings. \\
\hline$a_{2}$ & The reduction rate of green building. \\
\hline$\Omega$ & Amount of GHGs. \\
\hline$a_{3}$ & Rate of human originated GHGs. \\
\hline$a_{4}$ & The reduction rate of GHGs. \\
\hline$a_{5}$ & Production rate of ingredients by green buildings. \\
\hline$a_{6}$ & The adoption rate of ingredients by human communities. \\
\hline$a_{7}$ & The reduction rate of ingredients. \\
\hline$\Psi$ & Amount of human community. \\
\hline$a_{8}$ & The reduction rate of human communities. \\
\hline
\end{tabular}




\section{Model Illustration Analytical Analysis}

The system of non-linear ordinary differential equations (1)-(4) has been analysed in this section to find the stability conditions of the proposed model after performing the positivity analysis.
4.1 Positivity Analysis

Lemma 1: The solution of the state variables $G(t), C(t), I(t)$ and $H(t)$ of the proposed model is positive if $G(t) \geq 0, C(t) \geq 0, I(t) \geq 0$ and $H(t) \geq 0$ (Biswas, Hossain, \& Mondal, 2017).

Proof: To prove the considered lemma suppose the equation (1) of the model will be,

$\frac{d G}{d t} \geq \Lambda+a_{1} G C-a_{2} G \Rightarrow \frac{d G}{d t}+a_{9} G(t) \geq \Lambda \quad\left[\operatorname{Let}\left(a_{2}-a_{1} C\right)=a_{9}\right]$

$\therefore$ Integrating factor $=e^{\int a_{9} d t}=e^{a_{9} t}$. After multiplying $e^{a_{9} t}$ in both sides of equation (5) we get,

$e^{a_{9} t} \frac{d G}{d t}+e^{a_{9} t} a_{9} G(t) \geq e^{a_{9} t} \Lambda$. After integration, we get, $G e^{a_{9} t} \geq e^{a_{9} t} \frac{\Lambda}{a_{9}}+a_{10}$

where $a_{10}$ is constant.

According to the initial condition, $G(t)=G(0)$ at $t=0$. So, from equation (6) we get, $a_{10} \geq\left(\frac{\Lambda}{a_{9}}-G\right)$

By using the value of $a_{10}$ in equation (6) we get,

$G e^{a_{9} t} \geq e^{a_{9} t} \frac{\Lambda}{a_{9}}+\left(\frac{\Lambda}{a_{9}}-G\right) \Rightarrow G(t) \geq \frac{\Lambda}{a_{9}}\left(1+e^{-a_{9} t}\right)-e^{-a_{9} t} G(t)$. Hence $G(t) \geq 0$ at $t=0$ and $t \rightarrow \infty$.

Similarly, we can also obtain the lemma for others state variables and can mention that $C(t) \geq 0, I(t) \geq 0$ and $H(t) \geq 0$ at $t=0$ and $t \rightarrow \infty$.

Therefore, it is assumed that the state variables $G(t), C(t), I(t)$ and $H(t)$ of the proposed model of non-linear equations (1)-(4) are positive on behalf of Lemma 1.

\subsection{Equilibrium Analysis}

We will find two types of equilibrium for the propound models such as in section 4.2.1 (the global equilibrium point) and 4.2.2 (the trivial equilibrium point).

\subsubsection{Global Equilibrium}

The global equilibrium can be held by setting the rate of change of all the variables of the model to zero such as $\frac{d G}{d t}=\frac{d C}{d t}=\frac{d I}{d t}=\frac{d H}{d t}=0$ and by evaluating equations (1)-(4) such as:

$\Lambda+a_{1} G C-a_{2} G=0$

$\Omega-a_{1} G C+a_{3} H C-a_{4} C=0$

$a_{5} \mathrm{GI}-a_{6} H I-a_{7} I=0$

$\Psi+a_{6} H I-a_{8} H=0$

From equation (9) we have, $a_{5} G-a_{6} H-a_{7}=0[\because I \neq 0] \Rightarrow H=\frac{a_{5} G-a_{7}}{a_{6}}$

(11) Now by using the value of $H$ in equation (8) we get,

$\Omega-a_{1} G C+a_{3}\left(\frac{a_{5} G-a_{7}}{a_{6}}\right) C-a_{4} C=0 \Rightarrow C=\frac{\Omega a_{6}}{\left(a_{3} a_{7}+a_{4} a_{6}\right)-G\left(a_{3} a_{5}-a_{1} a_{6}\right)}$

Also, by using the value of $H$ in equation (10) we get,

$\Psi+a_{6} I\left(\frac{a_{5} G-a_{7}}{a_{6}}\right)-a_{8}\left(\frac{a_{5} G-a_{7}}{a_{6}}\right)=0 \Rightarrow I=\frac{a_{5} a_{8} G-a_{7} a_{8}-\Psi a_{6}}{a_{6}\left(a_{5} G-a_{7}\right)}$ 
Again, from equation (7) we have,

$C=\frac{a_{2} G-\Lambda}{a_{1} G} \Rightarrow \frac{\Omega a_{6}}{\left(a_{3} a_{7}+a_{4} a_{6}\right)-G\left(a_{3} a_{5}-a_{1} a_{6}\right)}=\frac{a_{2} G-\Lambda}{a_{1} G}$ [From equation (12)]

$\therefore G=\frac{\left(\Lambda a_{3} a_{7}+\Lambda a_{4} a_{6}\right)}{\left[\left(a_{2} a_{3} a_{7}+a_{2} a_{4} a_{6}\right)+\left(\Lambda a_{3} a_{5}-\Lambda a_{1} a_{6}\right)-a_{1} \Omega a_{6}\right]}=\alpha$ (constant say)

Now using the value of $G$ in equation (11), (12) and (13) we get,

$C=\frac{\Omega a_{6}}{\left(a_{3} a_{7}+a_{4} a_{6}\right)-\alpha\left(a_{3} a_{5}-a_{1} a_{6}\right)}, I=\frac{a_{5} a_{8} \alpha-a_{7} a_{8}-\Psi a_{6}}{a_{6}\left(a_{5} \alpha-a_{7}\right)}$ and $H=\frac{a_{5} \alpha-a_{7}}{a_{6}}$.

Let the global equilibrium point of the model is $E^{*}=\left(G^{*}, C^{*}, I^{*}, H^{*}\right)$ where,

$$
\begin{aligned}
& G^{*}=\alpha=\frac{\left(\Lambda a_{3} a_{7}+\Lambda a_{4} a_{6}\right)}{\left[\left(a_{2} a_{3} a_{7}+a_{2} a_{4} a_{6}\right)+\left(\Lambda a_{3} a_{5}-\Lambda a_{1} a_{6}\right)-a_{1} \Omega a_{6}\right]} ; C^{*}=\frac{\Omega a_{6}}{\left(a_{3} a_{7}+a_{4} a_{6}\right)-\alpha\left(a_{3} a_{5}-a_{1} a_{6}\right)} ; \\
& I^{*}=\frac{a_{5} a_{8} \alpha-a_{7} a_{8}-\Psi a_{6}}{a_{6}\left(a_{5} \alpha-a_{7}\right)} ; H^{*}=\frac{a_{5} \alpha-a_{7}}{a_{6}} .
\end{aligned}
$$

\subsubsection{Trivial Equilibrium}

For initialization of the mathematical model, we have the trivial equilibrium point at $E_{0}=\left(G_{0}, C_{0}, I_{0}, H_{0}\right)=(0,0,0,0)$.

\subsection{Stability Analysis}

If we try to establish real-world problems in mathematical analysis, we have to face a lot of complexity for defining them. But the non- linear scheme is the very best way to define the complex behaviour of the natural components in mathematical modelling. In a non-linear scheme, the stability theory helps to address the explicit solutions of the complex mathematical model. To find the stability of the proposed model first evaluate the Jacobean matrix over the system of equations (1)-(4) we get,

$$
J_{(G, C, I, H)}=\left[\begin{array}{cccc}
a_{2} C-a_{2} & a_{1} G & 0 & 0 \\
-a_{1} C & -a_{1} G+a_{3} H-a_{4} & 0 & a_{3} C \\
a_{5} I & 0 & a_{5} G-a_{6} H-a_{7} & -a_{6} I \\
0 & 0 & a_{6} H & a_{6} I-a_{8}
\end{array}\right]
$$

At the global equilibrium point $E^{*}=\left(G^{*}, C^{*}, I^{*}, H^{*}\right)$ the Jacobean matrix will be,

$$
J_{E^{*}\left(G^{*}, C^{*}, I^{*}, H^{*}\right)}=\left[\begin{array}{cccc}
a_{1} C^{*}-a_{2} & a_{1} G^{*} & 0 & 0 \\
-a_{1} C^{*} & -a_{1} G^{*}+a_{3} H^{*}-a_{4} & 0 & a_{3} C^{*} \\
a_{5} I^{*} & 0 & a_{5} G^{*}-a_{6} H^{*}-a_{7} & -a_{6} I^{*} \\
0 & 0 & a_{6} H^{*} & a_{6} I^{*}-a_{8}
\end{array}\right]
$$

which after solving by row-column operations becomes,

$$
J_{E^{*}}=\left[\begin{array}{cccc}
-a_{2} & a_{3} H^{*}-a_{4} & -a_{6} H^{*} & a_{3} C^{*}-a_{6} I^{*} \\
a_{2}-a_{1} C^{*} & -a_{1} G^{*} & -a_{6} H^{*} & -a_{6} I^{*} \\
a_{5} I^{*} & 0 & a_{5} G^{*}-a_{7}-a_{6} H^{*} & -a_{8}-a_{6} I^{*} \\
0 & 0 & 0 & -a_{8}
\end{array}\right]\left[\begin{array}{c}
r_{1}^{\prime}=r_{1}+r_{2} \\
r_{2}^{\prime}=r_{2}-r_{1} \\
r_{3}^{\prime}=r_{3}+r_{4} \\
c_{3}^{\prime}=c_{3}-a_{8} H^{*} \\
c_{4}^{\prime}=c_{4}-a_{8} I^{*}
\end{array}\right]
$$

from which we get the eigenvalues as, $\lambda_{1}=-a_{2}, \lambda_{2}=-a_{1} G^{*}, \lambda_{3}=a_{5} G^{*}-a_{6} H^{*}-a_{7}$ and $\lambda_{4}=-a_{8}$. Since all the eigenvalues are negative except $\lambda_{3}$. Hence, if $\lambda_{3} \leq 0$ then the equilibrium is locally asymptotically stable and also it is. 
At the trivial equilibrium $E_{0}=\left(G_{0}, C_{0}, I_{0}, H_{0}\right)=(0,0,0,0)$. Now after passing the trivial equilibrium $E_{0}$ through the Jacobean matrix of (15) we get,

$J_{E_{0}(0,0,0,0)}=\left[\begin{array}{cccc}-a_{2} & 0 & 0 & 0 \\ 0 & -a_{4} & 0 & 0 \\ 0 & 0 & -a_{7} & 0 \\ 0 & 0 & 0 & -a_{8}\end{array}\right]$

Therefore, we have the four eigenvalues as $\lambda_{1}=-a_{2}, \lambda_{2}=-a_{4}, \lambda_{3}=-a_{7}, \lambda_{4}=-a_{8}$. The stability of the equilibrium state is obtained by the eigenvalues $\lambda$ of the Jacobean matrix. So, the stability of the equilibrium states holds with the conditions depending on $\lambda$ that is: the steady-state is stable if the eigenvalue $\lambda<0$ or, the system is unstable if the eigenvalue $\lambda>0$. Since here all the eigenvalues are less than zero $(\lambda<0)$ so the stability condition is satisfied.

\section{Numerical Simulation with Resulting Accessories}

Our model targets to hold the accuracy of making the harmful sides of GHGs effective by implementing them into the green building system. The analytical result proofs the stability of the proposed model. Now to make a population favourable presentation, numerical or computer simulation is regarded as the best tool. We have used the MATLAB programming language to perform the numerical simulation of the proposed model. The objective of this simulation is to show the dynamical behaviour of green building dynamics for solving the GHGs emission and make a comprehension study to overlook the human communities proportionally.

The human community is the main tool for emitting unwanted GHGs. If there happens an increase in GHG emissions for different human activities, it directly forces all the biological creatures not to sustain perfectly. But naturally, the human community is an increasing factor. So, with the increasing number of human communities, the amount of GHGs will also rise. Our model targets to put on the increasing GHGs into green building systems to make the GHG component effective. If the discharge of rapid GHGs is happened by human communities, the green buildings take advantage of their technologies against GHGs. Being effective the green building produces several ingredients and also human communities become beneficial by getting the ingredients. After getting energies the human communities again take part in emitting GHGs and green buildings again soak these huge GHGs for energy production. The initial dynamic behaviour of the objects with the rapid GHGs emission is shown in Figure 5. Day by day the GHGs emission is rising for different human-made activities. Now, the performance of green buildings is to absorb these increasing GHGs $\left(a_{1}\right)$ from the atmosphere and make a potential effect on other species as shown in Figure 5. 

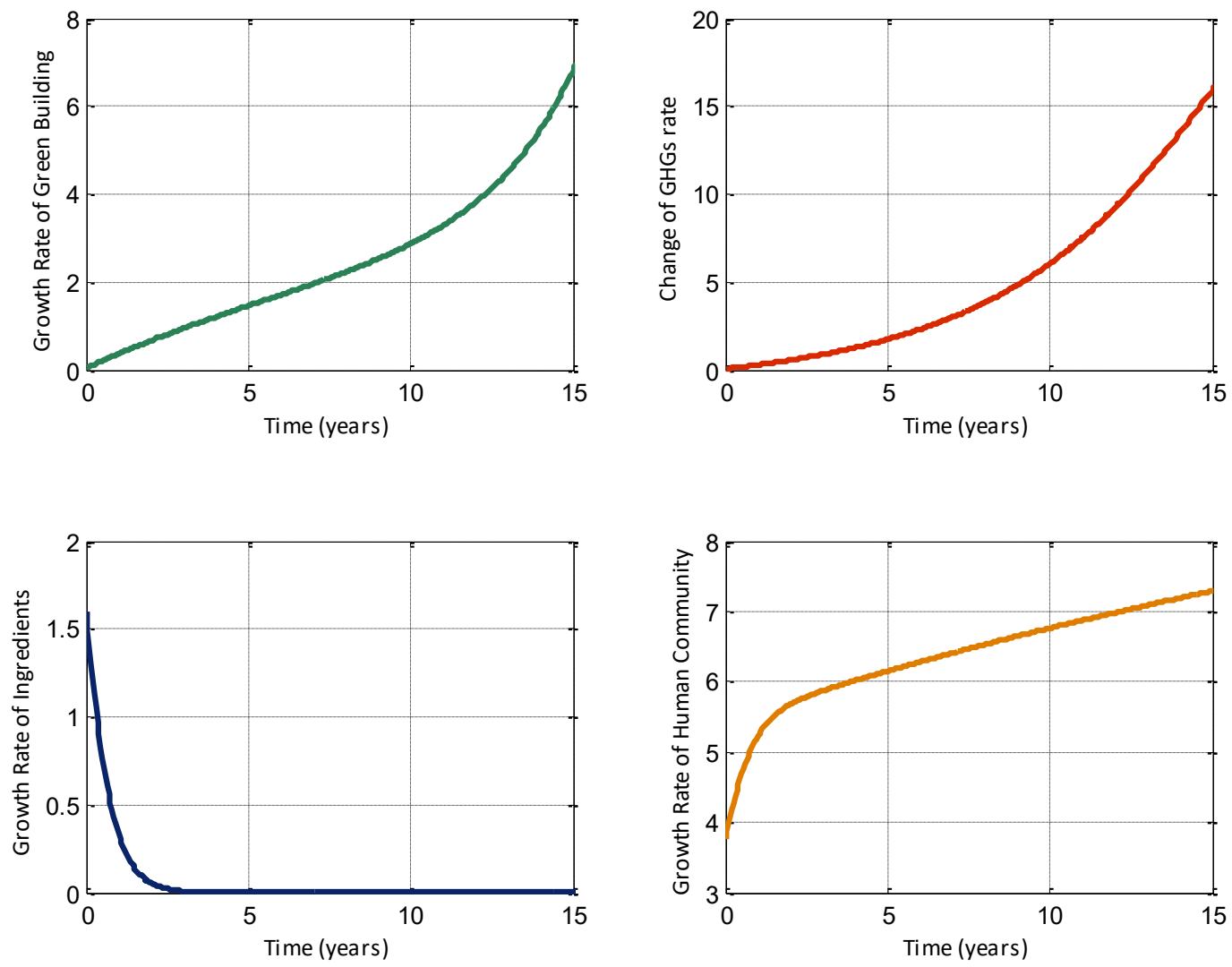

Figure 5. Numerical behaviours of the dynamic variables of the model (1)-(4) over time.

If the harmful GHGs are continuously absorbed by green buildings, the rate of green building is increasing continuously as shown in Figure 6 but the rate of GHGs is undoubtedly decreasing as represented in Figure 7. Due to the high absorption of GHGs, the green building can produce ingredients proportionally which is described in Figure 8. The human communities will be benefitted by getting the ingredients and can convert themselves in rising quantity as presented in Figure 9. The simulation scheme at different rates of GHGs absorption $\left(a_{1}\right)$ by green buildings is shown in Figure 6 and Figure 7 to predict that when green building absorbs less GHGs $\left(a_{1}\right)$ then green building rate is low but GHGs rate is high. But if green building absorbs GHGs at a high rate $\left(a_{1}\right)$ then green building becomes high where GHGs become low usually.

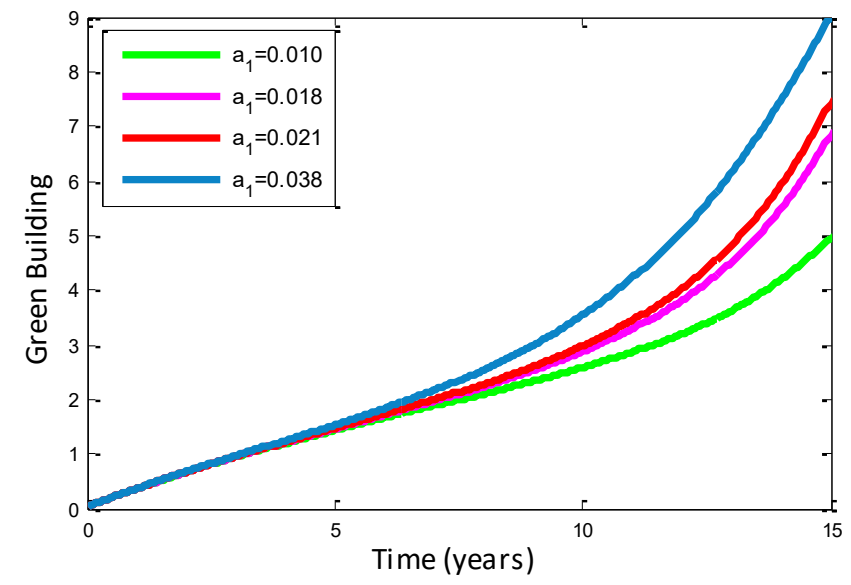

Figure 6. The growth rate of green building for different values of $a_{1}$. 


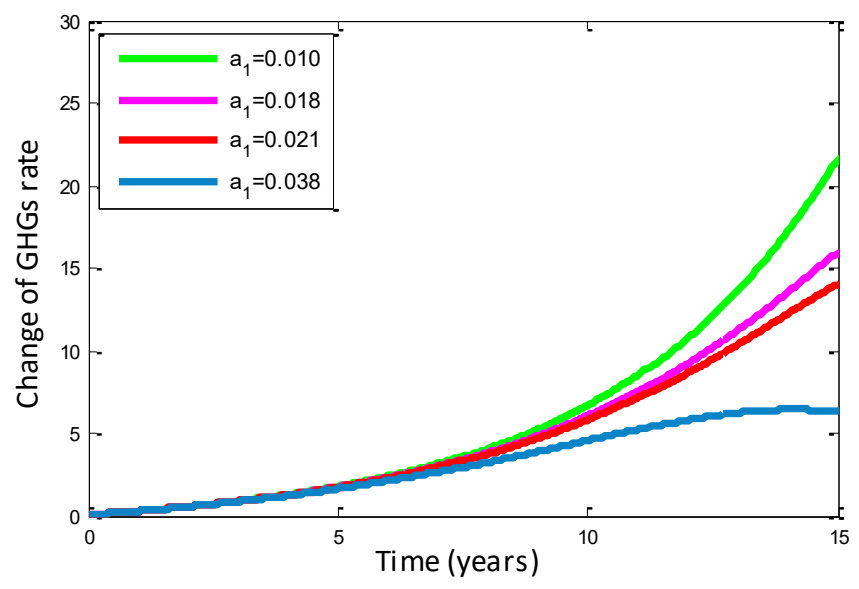

Figure 7. The decreasing rate of GHGs at different values of $a_{1}$.

Similar effects also fall on both human communities and ingredients. If green building absorbs low GHGs $\left(a_{1}\right)$, it generally produces fewer ingredients as described in Figure 8 and the contrary happens when green building takes more GHGs. Also, human communities show its rate low for absorbing less GHGs because when low GHGs absorption $\left(a_{1}\right)$ happens then green building also produces few ingredients. Moreover, the increment of human communities happens when green building gives more ingredients to human communities by absorbing more GHGs $\left(a_{1}\right)$ as shown in Figure 9.

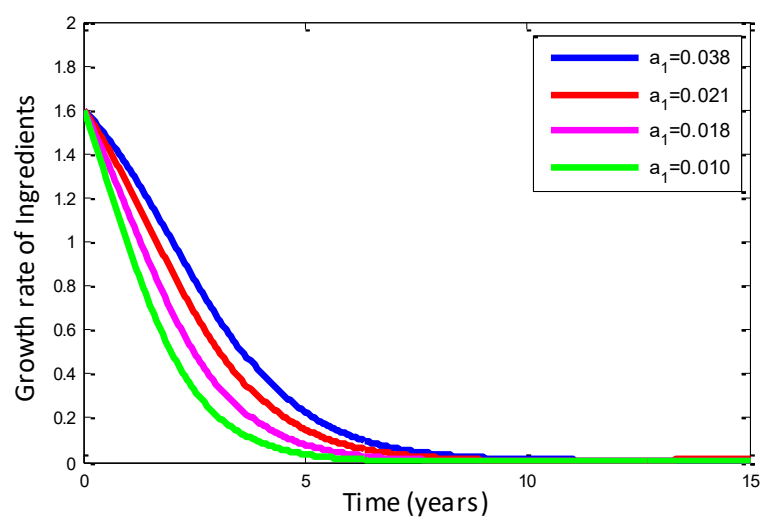

Figure 8. The growth rate of ingredients at different values of $a_{1}$.

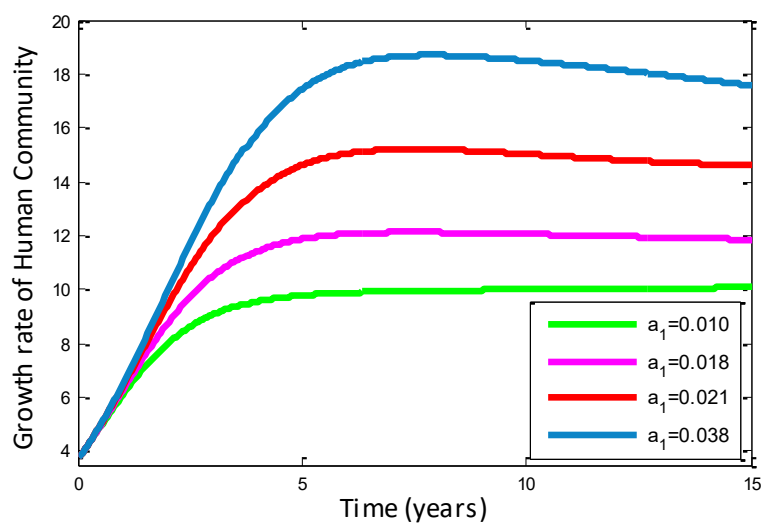

Figure 9. The growth rate of human communities at different values of $a_{1}$. 


\section{Conclusion}

To analyse any kind of natural assumption both analytically and numerically, mathematical modelling is a well-recognized tool. To describe the impact of green building on rapid GHG emissions, a non-linear mathematical model has been proposed in this study. The model is developed considering the effects of green buildings on human communities and GHGs absorption. After formulating the mathematical model is verified by the positivity analysis to confirm the existence of the considered state variables. Furthermore, the stability analysis is performed for both global and trivial equilibrium states. To verify and describe the accuracy of the analytical results of this study, numerical simulations are carried on. Overall, the results of this study conclude with the following points:

- Global warming is increasing at an alarming rate due to the extreme emission of GHGs.

- Different human activities especially building technologies are responsible for extreme GHGs emissions. As a result, the earth's climate, as well as atmospheric temperature, are rapidly changing.

- The amount of GHGs is proportionally decreased with the increasing green buildings.

- The production of ingredients and the absorption of GHGs proportionally depend on the number of green buildings.

- Green buildings can enhance the ingredients and human communities by absorbing more GHGs.

If the cyclic process of GHGs absorption is continued by introducing the technology of green buildings, the dream of future sustainable cities will no longer remain in only imagination. The green building is quite enough warrior to fight against the excess concentration of GHGs. Therefore, it is time to protect the world from global warming by controlling extreme emissions of GHGs and adopting green buildings as much as possible.

\section{Acknowledgement}

This research did not receive any specific grant from funding agencies in the public, commercial, or not-for-profit sectors.

\section{Conflict of interests}

The authors declare no conflict of interest.

\section{References}

Biswas, M. H. A., Hossain, M. R., \& Mondal, M. K. (2017). Mathematical modelling applied to sustainable management of marine resources. Procedia Engineering, 194, 337-334. https://doi.org/10.1016/i.proeng.2017.08.154

Biswas, H. A., Rahman, T., \& Haque, N. (2016). Modeling the potential impacts of global climate change in Bangladesh: an optimal control approach. Journal of Fundamental and Applied Sciences, 8(1), 1-19. https://doi.org/10.4314/jfas.v8i1.1

Broom, D., \& Gray, A. (2020). The US is set to rejoin the Paris climate agreement. Here's what you need to know. Regional Agenda: Environment and Natural Resource Security, Climate Change, GreenHorizon2020. World Economic Forum. Retrieved from: https://www.weforum.org/agenda/2020/11/pari s-agreement-climate-change-us-biden/

Edenhofer, O. R., Pichs-Madruga, R., Sokona, Y., Farahani, E., Kadner, S., Seyboth, K., Adler, A., Baum, I., Brunner, S., Eickemeier, P., Kriemann, B., Savolainen, J., Schlomer, S., Stechow, Z. V., Zwickel, T., \& Minx, J. C. (2014). Climate Change 2014: Mitigation of Climate Change. Working Group III Contribution to the Fifth Assessment Report of the Intergovernmental Panel on Climate Change. Cambridge University Press, Cambridge, United Kingdom and New York, USA.

https://www.ipcc.ch/site/assets/uploads/2018/0 2/ipcc_wg3 ar5 full.pdf

Gong, Y., \& Song, D. (2015). Life Cycle Building Carbon Emissions Assessment and Driving Factors Decomposition Analysis Based on LMDI-A Case Study of Wuhan City in China. Sustainability, https://doi.org/10.3390/su71215838

$7(12)$.

Grant, M., Pitt, H., \& Larsen, K. (2021). Preliminary 2020 Greenhouse Gas Emissions Estimates for China. Rhodium Group, New York.

Gul, M. S., \& Patidar, S. (2015). Understanding the energy consumption and occupancy of a multipurpose academic building. Energy and Buildings, $\quad 87, \quad 155-165$. https://doi.org/10.1016/j.enbuild.2014.11.027

Hanley, M. (2015). Which countries emit the most greenhouse gas? Global Agenda: Environment and Natural Resource Security, Global 
Governance, World Economic Forum. https://www.weforum.org/agenda/2015/07/cou ntries-emitting-most-greenhouse-gas/

Hausfather, Z. (2020). 2020 is on course to be the warmest year on record. Global Agenda: Environment and Natural Resource Security, Decarbonizing Energy, World Economic Forum.

Hethcote, H. W., \& van den Driessche, P. (1995). An SIS epidemic model with variable population size and a delay. Journal of Mathematical Biology, 34 , 177-194. https://doi.org/10.1007/BF00178772

Islam, A., \& Biswas, M. H. A. (2020). Modeling the Effect of Global Warming on the Sustainable Groundwater Management: A Case Study in Bangladesh WSEAS TRANSACTIONS On MATHEMATICS, 19 639-646. https://doi.org/10.37394/23206.2020.19.71

Jaffal, I., Ouldboukhitine, S.-E., \& Belarbi, R. (2012). A comprehensive study of the impact of green roofs on building energy performance. Renewable Energy, 43, 157-164. https://doi.org/10.1016/j.renene.2011.12.004

Kara, B. (2019). The impact of globalization on cities. Journal of Contemporary Urban Affairs, 3(2), 108-113.

https://doi.org/10.25034/ijcua.2018.4707

Kaygusuz, K. (2007). Energy for Sustainable Development: Key Issues and Challenges. Energy Sources, Part B: Economics, Planning, and Policy, 2(1), 73-83. https://doi.org/10.1080/15567240500402560

Larsen, K., Pitt, H., Grant, M., \& Houser, T. (2021). China's Greenhouse Gas Emissions Exceeded the Developed World for the First Time in 2019. Rhodium Group, New York. https://rhg.com/research/chinas-emissionssurpass-developed-countries/

Lebling, K., Friedrich, J., \& Waite, R. (2020). Climate action must progress far faster to achieve $1.5^{\circ} \mathrm{C}$ goal. Global Agenda: Environment and Natural Resource Security, Green New Deals, World Economic Forum. https://www.weforum.org/agenda/2020/11/cli mate-action-emissions-target-paris-agreement

Liu, H., \& Lin, B. (2016). Ecological indicators for green building construction. Ecological Indicators,
67 ,

68-77

https://doi.org/10.1016/j.ecolind.2016.02.024

Mandal, S., Islam, M. S., \& Biswas, M. H. A. (2020). Modeling the Impact of Carbon Dioxide on Marine Plankton. INTERNATIONAL JOURNAL OF MATHEMATICS AND COMPUTERS IN SIMULATION, 14, 197-202. https://doi.org/10.46300/9102.2020.14.25

Mandal, S., Islam, M. S., \& Biswas, M. H. A. (2021). Modeling the potential impact of climate change on living beings near coastal areas. Modeling Earth Systems and Environment, 7(3), 1783-1796. https://doi.org/10.1007/s40808-020-00897-5

Marchetti, C., Meyer, P. S., \& Ausubel, J. H. (1996). Human population dynamics revisited with the logistic model: How much can be modeled and predicted? Technological Forecasting and Social Change, 52(1), 1-30. https://doi.org/10.1016/0040-1625(96)00001-7

Mardiana, A., \& Riffat, S. B. (2013). Review on physical and performance parameters of heat recovery systems for building applications. Renewable and Sustainable Energy Reviews, 28, 174-190. https://doi.org/10.1016/j.rser.2013.07.016

Metz, B., Davidson, O., Bosch, P., Dave, R., \& Meyer, L. (2007). Climate Change 2007: Mitigation of Climate Change. Cambridge University Press, Cambridge, United Kingdom and New York, $N Y$, USA. https://www.ipcc.ch/site/assets/uploads/2018/0 3/ar4_wg3_full_report-1.pdf

Mondal, M. K., Hanif, M., \& Biswas, M. H. A. (2017). A mathematical analysis for controlling the spread of Nipah virus infection. International Journal of Modelling and Simulation, 37(3), 185-197.

https://doi.org/10.1080/02286203.2017.132082 $\underline{0}$

Nyári, J. (2011). Carbon footprint of construction products: a comparison of application of individual Environmental Product Declarations and Building Information Modeling software. https://www.theseus.fi/handle/10024/93737

Pacala, S., \& Socolow, R. (2004). Stabilization Wedges: Solving the Climate Problem for the Next 50 Years with Current Technologies. Science, 305(5686), 968-972. https://doi.org/10.1126/science.1100103 
Pal, S. K. D. (2017). Feasibility of a Carbon Consumption Tax for sustainable development-A case study of India. Journal of Contemporary Urban Affairs, 1(3), 18-23. https://doi.org/10.25034/ijcua.2018.3674

Parvin, T., Islam, A., Mondal, P. K., \& Biswas, M. H. A. (2020). Discrete Type SIR Epidemic Model with Nonlinear Incidence Rate in Presence of Immunity. WSEAS TRANSACTIONS on BIOLOGY and BIOMEDICINE, 17, 104-118. https://doi.org/10.37394/23208.2020.17.13

Pollack, H. N., Hurter, S. J., \& Johnson, J. R. (1993). Heat flow from the Earth's interior: analysis of the global data set. Reviews of Geophysics, $31(3)$, 267-280. https://doi.org/10.1029/93RG01249

Rahbarianyazd, R., \& Raswol, L. (2018). Evaluating energy consumption in terms of climatic factors: A case study of Karakol residential apartments, Famagusta, North Cyprus. Journal of Contemporary Urban Affairs, 2(1), 45-54. https://doi.org/10.25034/ijcua.2018.3658

Reddy, S. (2016). The environmental benefits of building green-an overview. International Journal of Engineering and Management Research (IJEMR), 6(6), 109-113.

Reza, A. K., Islam, M. S., \& Shimu, A. A. (2017). Green Industry in Bangladesh: An Overview. Environmental Management and Sustainable Development, 6(2), 124-143. https://doi.org/10.5296/emsd.v6i2.11027

Rezaie, B., Esmailzadeh, E., \& Dincer, I. (2011). Renewable energy options for buildings: Case studies. Energy and Buildings, 43(1), 56-65. https://doi.org/10.1016/j.enbuild.2010.08.013

Röck, M., Saade, M. R. M., Balouktsi, M., Rasmussen, F. N., Birgisdottir, H., Frischknecht, R., Habert, G., Lützkendorf, T., \& Passer, A. (2020). Embodied GHG emissions of buildings - The hidden challenge for effective climate change mitigation. Applied Energy, 258(114107), 112.

https://doi.org/10.1016/j.apenergy.2019.11410 7

Roper, W. (2021). This chart shows how global temperatures have risen since 1950. Global Agenda: Climate indicators, How to save the planet, World Economic Forum. https://www.weforum.org/agenda/2021/01/cli mate-change-global-warming-carbon-dioxideemissions-science/
Roston, E. (2021). 2020 Ties for Hottest Year in the Hottest Decade Ever. Climate Adaptation, Bloomberg Green.

Sasanpour, F. (2017). Livable city one step towards sustainable development. Journal of Contemporary Urban Affairs, 1(3), 13-17. https://doi.org/10.25034/ijcua.2018.3673

Shanta, S. S., \& Biswas, M. H. A. (2020). The impact of media awareness in controlling the spread of infectious diseases in terms of SIR model. Mathematical Modelling of Engineering Problems, 7(3), 368-376. https://doi.org/10.18280/mmep.070306

Shawkat, L. W., Al-Din, S. S. M., \& Kuzović, D. (2018). Opportunities for Practicing Sustainable Building Construction in Kurdistan Region, Iraq. Journal of Contemporary Urban Affairs, 2(1), 69-101. https://doi.org/10.25034/ijcua.2018.3665

Smeets, E. M. W., Faaij, A. P. C., Lewandowski, I. M., \& Turkenburg, W. C. (2007). A bottom-up assessment and review of global bio-energy potentials to 2050. Progress in Energy and Combustion Science, 33(1), 56-106. https://doi.org/10.1016/j.pecs.2006.08.001

Sovacool, B. K., \& Brown, M. A. (2010). Twelve metropolitan carbon footprints: A preliminary comparative global assessment. Energy Policy, 38(9), 4856-4869. https://doi.org/10.1016/i.enpol.2009.10.001

Tathagat, D., \& Dod, R. D. (2015). Role of green buildings in sustainable construction-need, challenges and scope in the Indian scenario. IOSR Journal of Mechanical and Civil Engineering (IOSR-JMCE) 12(2), 01-09.

Wang, S., Fang, C., Guan, X., Pang, B., \& Ma, H. (2014). Urbanisation, energy consumption, and carbon dioxide emissions in China: A panel data analysis of China's provinces. Applied Energy, 136 , 738-749. https://doi.org/10.1016/j.apenergy.2014.09.059

Wu, X., Peng, B., \& Lin, B. (2017). A dynamic life cycle carbon emission assessment on green and nongreen buildings in China. Energy and Buildings, 149 , 272-281. https://doi.org/10.1016/j.enbuild.2017.05.041

Yau, Y. H., \& Hasbi, S. (2013). A review of climate change impacts on commercial buildings and their technical services in the tropics. 
Renewable and Sustainable Energy Reviews, 18 430-441. https://doi.org/10.1016/j.rser.2012.10.035

Yilmaz, D. G. (2021). Model Cities for Resilience: Climate-led Initiatives. Journal of Contemporary Urban Affairs, 5(1), 47-58. https://doi.org/10.25034/ijcua.2021.v5n1-4

Zhao, L., Oleson, K., Bou-Zeid, E., Krayenhoff, E. S., Bray, A., Zhu, Q., Zheng, Z., Chen, C., \&
Oppenheimer, M. (2021). Global multi-model projections of local urban climates. Nature Climate Change, 11, 152-157. https://doi.org/10.1038/s41558-020-00958-8

Zhu, C., \& Yin, G. (2009). On competitive LotkaVolterra model in random environments. Journal of Mathematical Analysis and Applications, 357(1), 154-170. https://doi.org/10.1016/j.jmaa.2009.03.066 